\title{
La Ética es la llave del futuro de la Comunicación
}

\author{
Cristina BARANDA DEL CAMPO \\ cbcb.rm@gmail.com \\ Doctora en Ciencias de la Información por la UCM \\ (a) CBarandaCampo
}

Recibido: $10 / 02 / 2014$

Aceptado: 15/03/2014

\section{RESUMEN}

El profesional de la información es un mediador social, su trabajo marca el pasado, el presente y el futuro de la sociedad. Ha de obrar con criterio objetivo, veraz y responsable. Pues su labor marcará los comportamientos de los ciudadanos y éstos obrarán de una manera o de otra según la actitud informativa que haya tomado el profesional tanto si está elaborando la información como si está documentando un hecho o creando una fuente informativa.

Es esencial proceder con objetividad en cualquier acción, de esto dependerá que se den buenos resultados o no. Sin aditivos, sin opiniones, sin frases o informaciones excesivas que empañen, distraigan o enturbien el auténtico significado del hecho real. Y esa realidad es el origen de un documento y ese de otro y éste de otros tantos. Y si en el camino se van enrareciendo los productos siguientes son diferentes del objeto inicial.

Palabras clave: Ética, moral, justicia, veracidad, documento, información, influencias, reto profesional, conductas, valores, principios morales, documentalista, periodista, comunicador, esfuerzo ético.

\section{Ethics is the key to the future of communication}

\begin{abstract}
The information professional is a social mediator, his work marks the past, the present and the future of society. It must act with criterion objective, truthful and responsible. As their work will mark the behaviors of citizens and these shall act in a way or another according to the informative attitude taken both professional if it is developing information as if you are documenting a fact or creating an informative source.

It is essential to proceed with objectivity in any action, this will depend on that good results are given or not. No additives, no opinions, no phrases or excessive information that tarnish, distracted or slowing the authentic meaning of the real fact. And that reality is the origin of a document and that of another and of many others. And if on the road the following products are thinning are different from the initial object.

Keywords: Ethics, morality, justice, truthfulness, document, information, influence, professional, challenge, behaviors, values, morals principles, documentalist, journalist, communicator, ethical effort.
\end{abstract}

\section{INTRODUCCIÓN}

La ética es importante en todas las facetas del ser humano, cualquier actuación que realice define su comportamiento. Obra bien o actúa mal. Y cualquier actividad profesional va marcada por la conducta de sus protagonistas. 
La información ha de ser verídica, cierta, objetiva y ajustada a la realidad. Debe resultar completa y sin manipular, comprensible, asequible y ágil. En cambio la opinión, que es otra forma de comunicación pero subjetiva, valorativa, adornada de elementos de juicio, es muy necesaria en cualquier régimen democrático, gracias a ella la participación del ciudadano es muy necesaria, porque al poder aportar sus deseos, opiniones y vicisitudes, se pueden mejorar los sistemas organizativos.

El informador ha de ser sensato y no sobrepasar las barreras de su poder sino ser consciente de que hace un servicio público a los demás y no debe cegarse con ideas, opiniones o juicios subjetivos.

Veracidad, imparcialidad, justicia son cualidades difíciles de lograr al cien por cien y principios básicos de la información que han de ser respetados por el informador de la misma manera que ha de tener en cuenta

\section{ORIGEN Y CONCEPTO DE ÉTICA}

Si la Ética es la ciencia que estudia lo bueno y lo malo y enseña a distinguirlo cabe pensar por lógica que esta disciplina ayuda al ser humano a concienciarse sobre sus actos con lo que le rodea, ya sean personas, animales o cosas. Es bueno saber aplicar las costumbres, en definitiva aplicar la moral usando los valores de justicia, libertad, solidaridad, honestidad, etc. lo que la cultura de vida nos ha ido enseñando a desplegar como valores buenos para pasear por la vida de una forma más honesta y digna. Cuando la persona evita el mal y realiza el bien está ejerciendo su ética con la ayuda de su propia conciencia que le dicta un comportamiento adecuado por el que se sentirá bien o mal, y por el que será considerado como ser humano.

Para actuar con ética hay que seguir un proceso y el método, como punto de partida de la ética, consiste primeramente en realizar una observación, utilizando los sentidos en forma acuciosa, penetrante y amplia, luego debemos evaluar en una enorme variedad de calificativos y finalmente una percepción axiológica que es medir los valores que ya ha percibido, según la etapa de la ida en la que se encuentre ${ }^{I}$. Este hecho marcará como está portándose la persona que está atada a la crítica en todo momento. Si el sujeto actúa con dobles intereses, lo está haciendo en ese instante sin ninguna ética, olvidándose que existen los valores buenos y le acarreará muchos problemas.

La palabra ética proviene del griego ethos cuyo significado es costumbre. Esta ciencia se relaciona estrechamente con la moral tanto que ambos términos se confunden con frecuencia. Ambos términos tienen el mismo significado etimológico con la diferencia que la moral proviene del latín mos. La ética no receta ninguna norma o conducta, ni ordena ni dicta directamente que debemos hacer. Su objetivo es clarificar que es lo moral, como se fundamenta una moral racionalmente y como se ha de utilizar en los distintos ámbitos de la vida social.

${ }^{1}$ Idcupn.files.wordpress.com/.../definición-de-ética 
Luego si la ética estudia la moral y determina qué es lo bueno y desde ese criterio como se debe obrar, resulta que es la ciencia o la teoría del comportamiento moral.

La Moral tiene una base social porque es un conjunto de normas establecidas ya en el seno de una sociedad, en cambio la Ética surge como rama de la filosofía desde la interioridad de las personas, como resultado de su propia reflexión y de su propia elección.

\section{LA ÉTICA DE PERIODISTAS Y DOCUMENTALISTAS AL SERVICIO DE LA INFORMACIÓN REAL}

La educación en la infancia marca una impronta en la persona que perdura toda la vida. Según se asimilen los valores aprendidos a temprana edad así serán las actuaciones posteriores. El valor del diálogo y el respeto a la opinión del otro sin imponer la propia, son fundamentales. Los medios de comunicación educan al niño, rompen barreras y los padres han de enseñarle para racionalizar la información, rebatirla, criticarla, defenderla, en definitiva valorarla.

Los profesionales de la información realizan una tarea social transmitiéndola y éste es un servicio muy valioso. Para ello han de utilizar su ética y tener una actitud moral ejemplar, con el fin de que la información sea fidedigna, objetiva, completa y asimilable. La prensa debe ser plural en opiniones pero no en informaciones, éstas han de ser ciertas. Ya en la Declaración de los Derechos Humanos, en su artículo 19, se hablan de tres facultades que constituyen el contenido del derecho a la información: investigar, recibir y difundir. Lo reflejaba Ángel Cuenca Molina ${ }^{2}$ (Cuenca Molina, 1999) al explicar que en primer lugar el derecho a la información requiere otro subderecho que es el de acceder directamente a las fuentes. En segundo lugar, el derecho a la información incluye el de recibir informaciones y opiniones y la posibilidad de negarse a recibirlas y en tercer lugar el subderecho a la difusión de informaciones y opiniones eliminando los obstáculos que se opongan. Pues si está reconocido el derecho a informar o a ser informado en nuestra Constitución de 1978, puesto que está incluido en el Título I de los Derechos y Deberes Fundamentales, en su capítulo $2^{\circ}$ Derechos y Libertades, sección $1^{\text {a }}$ (de los Derechos Fundamentales y de las Libertades Políticas) y artículo 20: se reconocen y protegen los derechos a expresar y difundir libremente los pensamientos, ideas y opiniones mediante la palabra, el escrito o cualquier otro medio de reproducción, a la producción y creación literaria, artística, científica y técnica, a la libertad de cátedra, a comunicar o recibir libremente información veraz por cualquier medio de difusión, entonces también la ley regulará el derecho a la cláusula de conciencia y al secreto profesional en el ejercicio de estas libertades. Y está reconocida la libertad como indispensable para el ejercicio del derecho a la información, ha de estar garantizada sin limitaciones

2 Cuenca Molina, Ángel: Ética de la comunicación. Anales de Documentación, $\mathrm{n}^{\mathrm{o}} 2$, 1999, pp. 16-17. 
más que las establecidas por la ley, para asegurar el reconocimiento y el respeto de los derechos y libertades de los demás. Si el profesional de la información respeta todas esas facultades, ha de pensar detenidamente antes de informar y emitir sus contenidos, ya que de sus actuaciones dependerán muchos comportamientos.

\section{LO QUE EXIGE EL MEDIO Y LA EMPRESA}

Los centros de información y de las bibliotecas públicas, académicas y escolares responden a unas determinadas tradiciones que evolucionan de manera diferente respondiendo a las necesidades de que las instituciones del país apoyen el desarrollo económico. A la hora de elegir publicaciones en una biblioteca, por ejemplo, no se deben negar determinadas informaciones a los usuarios, se debe prestar un servicio adecuado y competente y se deben facilitar toda clase de búsquedas sin poner trabas que las dificulten.

Ya el profesor Thomas Froelich ${ }^{3}$ hacía en 1995 revisión de algunas situaciones conflictivas en documentación y bibliotecas. El documentalista no puede ni debe dar opiniones sobre los propios temas de la búsqueda que le hacen, no debe asesorar, debe limitarse a dar la información que le piden ya cuando elige unos $\mathrm{u}$ otros documentos están realizando un juicio valorativo de selección por muy objetivo que sea. El copyright también plantea un problema de ética, pues muchas veces se salta la legislación y desprotegen los datos y los archivos. Hay que exigirse a uno mismo mucha responsabilidad y rectitud para obrar bien y no saltarse las normas. Es muy difícil, pero no imposible ser ético. Los productores de las bases de datos deben responsabilizarse de la exhaustividad y de la exactitud de las mismas. Deben procurar que la información que recopila no sea sesgada y está correctamente indizada ${ }^{4}$ El profesional de la información, bien sea el periodista, bien sea el documentalista, debería poseer equilibrio en sus ideas, su profesión y la empresa o medio donde realiza su tarea profesional, pero en ocasiones es una utopía y le crea problemas de conciencia e incluso laborales. Actualmente hay mucho que comunicar y suceden numerosas noticias para contar y documentar, y por ello resulta apasionante ser comunicador, pero ocurre también que la información sumerge al profesional en un campo lleno de obligaciones y decisiones éticas. No se debe excusar la objetividad o subjetividad de un profesional por causas externas o situaciones políticas o económicas como la crisis actual. Los profesionales que viven de los medios, sea cual sea su puesto, prefieren obedecer a un código ético que les regule, que les guíe su proceder periodístico, no les gusta dejarlo a su elección, pues ésta sea cual fuere puede ocasionarles problemas. Pero no todos los medios tienen sistema deontológico que les

\footnotetext{
${ }^{3}$ Froehlich, Thomas J.: Ética e información, artículo El profesional de la información; 1995 www.elprofesionaldelainformación.com/contenidos/1995/septiembre/tica_e_inf

${ }^{4}$ Froehlich, Thomas J.: Ética e información, artículo El profesional de la información; 1995 www.elprofesionaldelainformación.com/contenidos/1995/septiembre/tica_e_inf
} 
autoregule. La sociedad se fía que los profesionales de la información buscan la verdad y que lo hacen en fuentes fiables. En un estudio conjunto entre Servimedia y la compañía Estudio de Comunicación, presentado en el curso "Ética, credibilidad y confianza en los Medios de Comunicación del siglo XXI" en los cursos de verano 2012 de la Universidad Complutense en San Lorenzo de El Escorial se concluye que los profesionales destacan la importancia de la transmisión oral de los principios éticos a través del diálogo, el trabajo en equipo y el ejemplo de los periodistas veteranos. Los medios que cuentan con la figura del defensor del usuario son los más predispuestos a tener en cuenta la opinión de su audiencia en cuestiones de ética periodística y los que tienen más abiertos canales de diálogo con éstos ${ }^{5}$

\section{CONTAR Y RETRATAR LO QUE ACONTECE TAL COMO ES}

Es mejor relatar la verdad que distorsionarla para ponerla un precio. Es más digno plasmar los hechos, las costumbres, la cultura, la belleza y el horror, sea cual sea su grado, todos aquellos valores que conforman la memoria histórica. Una memoria surgida de los pequeños pero grandes detalles que está ahí para ser captada por el buen fotógrafo, el buen informador y no para el que busca el lucro y la moldea a su antojo para obtener unos fines determinados. Pero ¿cómo se logra que la ética del documentalista y del periodista sea intachable? Se consigue desde uno mismo, desde la interiorización y reflexión de la importancia del acto de informar verídicamente. No es una tarea fácil pero es muy grata si se lleva a cabo con rigor, pues la conciencia luego se fortalece al actuar debidamente. Intervienen muchos factores que enturbian la realidad y hacen tambalear el ejercicio de lo correcto.

Tanto la imagen como el texto van a constituir en el tiempo un documento histórico y tienen una relevancia cada vez más influyente. Los historiadores dejaron un poco al margen las imágenes, buscaban solo textos literarios y testimonios orales. Pero hay otros aspectos de la vida como la cultura material, la historia del cuerpo, las costumbres, la vida cotidiana, que no pueden ser abarcados sin el testimonio de las imágenes. Las ideas experimentan un cambio, evolucionan y las imágenes captan y dejan entrever esos indicios, ya que ofrecen un testimonio de lo que plasman y permiten que el observador haga sus interpretaciones. Las fotos tienen una función social que es la de memoria vital, gracias a la fotografía irrumpen perdurablemente los trabajadores y la gente común en la memoria colectiva, igual que solo desde la invención del fonógrafo hay constancia directa de la música popular ${ }^{6}$ (Muñoz Molina, 2008). El trabajo del documentalista de

5 Servimedia, Estudio de Comunicación y colaboración de FAPE: "La ética en la empresa periodística y su profesionales"(Estudio conjunto, julio de 2012; 25 aniversario cursos de verano Universidad Complutense, San Lorenzo del Escorial)

${ }^{6}$ Muñoz Molina, A.: Memoria fotográfica; artículo periódico EL PAÍS; 5 abril 2008 
información ha de plasmar el mundo tal como es sin aditivos para que pase a la historia como un mensaje informativo de lo que realmente ha pasado, lo que está aconteciendo delante de nuestros ojos y oídos y que en poco tiempo si no se capta se convierte en olvido, sin aditivos ni colorantes sin malear sin imprimirle el sello personal, tal y como ocurre, tal y como fue, es y será.

\section{EL ESFUERZO DE CUMPLIR CON LA ÉTICA}

Realmente la información requiere una voluntad de trabajo encomiable al obtenerla, al asumirla, al conseguir retenerla para convertirla en mensaje y posterior documento, al tratarla sin distorsionarla, sin ensuciarla de adornos que la alejan del hecho real. El profesional de la información realiza el esfuerzo de cumplir con su ética, pues al mismo tiempo que acontece el hecho ocurren unas circustancias exteriores que lo pueden cambiar, que son importantes para comprenderlo pero que según como influyan en el testigo convertirán el hecho en otra noticia o documento o lo respetarán tal y como ha sido. Su esfuerzo por informar o documentar un mensaje de manera honesta le otorgarán credibilidad y confianza.

Para conseguir la exquisitez los periodistas y documentalistas han de cooperar en sus tareas. En el fondo todos estos profesionales están deseando que alguien marque un directorio sobre la ética de la información, que no se difumine la conciencia moral y que se traduzca en pautas prácticas actuales que contengan todos los conflictos existentes por las nuevas tecnologías, por Internet, por una información veraz, por los derechos de autor. Estos profesionales han de formar y enseñar al usuario a utilizar y consumir con respeto la información. El mejor medio que tienen los profesionales para lograr este objetivo de educar al usuario es dar ejemplo produciendo ellos mismos un documento o una información objetiva, justa y veraz.

Pero no solo informar a los que tienen el poder de la información y del criterio, lo difícil y meritorio consiste en trabajar con dignidad para los que realmente lo necesitan, los desinformados y faltos de medios para lograrlo. El catedrático Antonio García Gutiérrez lo apuntaba ya hace una década: esta última pretensión es una llamada a la ética y a la conciencia profesional que solo haría cambiar las prioridades de la investigación que sólo haría cambiar las prioridades de la investigación, de la formación y de las prácticas en el mundo a un reducido grupo de incorfomistas?. El profesor García Gutiérrez se cuestionaba: ¿solo debemos pensar en clientes $y$ no en usuarios? $Y$ ¿deben pertenecer estos usuarios a las élites (científicos, políticos, periodistas) que ya tienen el acceso a

${ }^{7}$ García Gutiérrez, A.: "Notas sobre procesos reflexivos y funciones en los nuevos especialistas de información: aproximación a los perfiles formativo e investigador". ÁMBITOS N ${ }^{\mathrm{o}} 3-4,2^{\circ}$ semestre $1999-1^{\circ}$ semestre 2000 (pp. 33-41) 
la información $?^{8}$ El derecho humano a la información, primordial en el conocimiento de la naturaleza humana, ha de remover la conciencia de todos, pero principalmente en periodistas y documentalistas.

\section{LA ÉTICA COMO CLAVE DEL FUTURO INFORMADOR}

La Comunicación como profesión constituye una tarea única para la sociedad, necesaria y es decisiva su influencia. Por ello el informador debe comprometerse a que su trabajo sea digno pues los resultados dependerán de su modo de actuar. En la facultad se instruye Ética de la Documentación, se enseña a entender qué es y qué significa la Ética y la Deontología profesional, logrando aumentar con ello la comprensión de la Documentación su qué, su por qué y su para qué. Con este aprendizaje el alumno se educa en la creciente necesidad de aglutinar un perfil profesional pleno de saber, saber ser y saber hacer con elevada cualificación, competencia y responsabilidad. Debe ampliarse su formación en esta materia fundamental que es la Ética, pues de que sirve saber mucho si no se ha aprendido a transmitir esa cultura objetivamente comunicándola a la sociedad lo más exacta y veraz posible. Esa disciplina fundamental que es la Ética se muestra como la clave del futuro informador.

En cualquier cadena periodística o documental la ética es primordial. Desde la producción de un documento o información periodística pasando por su gestión hasta su consumo por los usuarios es necesario actuar con comportamientos éticos y de disciplina bien sean regidos por el medio o marcados por uno mismo. De acuerdo con la Special Libraries Association', los profesionales de la información requieren:

- Sentido de compromiso con la excelencia del servicio.

- Capacidad para enfrentar y buscar el reto, así como para identificar nuevas oportunidades dentro de la biblioteca y fuera de ella.

- Visión amplia

- Facilidad para buscar asociaciones y alianzas.

- Habilidad para crear ambientes de mutuo respeto y confianza.

- Habilidades para comunicarse.

- Saber trabajar bien en equipo.

- Tener espíritu de líder.

8 Ídem: García Gutiérrez, A.

${ }^{9}$ Special Libraries Association: Abels, E., Jones, R., Latham, J. Magnoni, D. Gard Marshall, J., traducido al español por Lau, J.: Competencias para profesionales de la información del siglo XXI, junio 2003

http://www.sld.cu/galerias/pdf/sitios/bmn/competencias_profesionales_trabajadores_inf ormacion_sla.pdf 
- Saber planificar, priorizar y enfocar los aspectos más críticos.

- Estar comprometidos con la formación continuada y el desarrollo de su carrera profesional.

- Habilidades para los negocios y para captar las nuevas oportunidades.

-Reconocer el valor de la cooperación y la solidaridad entre los profesionales.

- Ser flexibles y tener una actitud positiva ante los continuos cambios.

Se producen cotidianamente dilemas éticos, momentos en los que hay decidirse por una conducta buena o mala. Algunos llevan implícita una carga de responsabilidad para el profesional de la información y la causa es la importancia de la información y las circunstancias que la rodean, constituyendo un recurso principal cuando se decide alguna cuestión.

Si el usuario dicta que es relevante para él y que demanda al informador, el profesional ha de tener claro sus valores morales y tratar éticamente la información y el documento que ofrece, si por el contrario se deja influenciar por las circunstancias exógenas al hecho en sí, estará decorando la realidad a su gusto y medida.

Actualmente los usuarios tienen a su alcance todo tipo de informaciones y de herramientas informáticas. Pero necesitan de un especialista que les guíe en su utilización, en su búsqueda y participación. Ya lo apuntaba el profesor Rojas Mesa al indicar que: para promover el uso más eficaz y participativo de estos recursos, localizar la información realmente relevante y de respaldo científico, está el especialista de la información. De ellos, se espera que se conviertan en fieles promotores y maestros del respeto a la propiedad intelectual y de la información, tanto en forma electrónica como impresa, sólo interesados en el uso y acceso democrático a la información ${ }^{10}$. Los profesionales de la información llevan consigo unas tareas implícitas que le obligan con la sociedad como actuar con diligencia profesional, usando medios legales, investigando $\mathrm{y}$ aportando conclusiones, siendo nobles y honrados, respetando los derechos propios y de los demás, no hacer diferencias con nadie dando oportunidades a cualquiera para obtener la información con las nuevas tecnologías y desarrollando nuevos conceptos para la información, velando por el secreto de la información, en definitiva siendo éticos en cada actuación.

Es muy necesaria la claridad para definir un comportamiento ético, y no siempre se consigue en la era tecnológica actual y con el uso Internet, por muy coherente y racional que se pretenda ser. Con la explosión de las nuevas tecnologías, la barrera que distingue lo correcto de lo incorrecto se ha difuminado. Numerosas veces, los profesionales de la información no son juiciosos y olvidan

${ }^{10}$ Rojas Mesa, Y., Cabrales Hernández, G., Gregorio Chaviano, O., Santos Jiménez, M. y Molina Gómez, A.: La ética: un nuevo reto para el profesional de la información del siglo XXI. ACIMED (ISSN 1024-9435) V.12n.2- Ciudad de La Habana, mar-abr 2004 
las consecuencias éticas de sus actos. Trabajan con hábitos y con rutina. Los litigios éticos surgen al aparecer situaciones especiales.

La Ética supone un aprendizaje arduo para el informador pero debe establecerse como un objetivo indispensable. Algunos autores consideran que en la esfera estrictamente profesional, la ética proporciona un marco de trabajo para dirigir las funciones esenciales de los especialistas, establecer políticas y desarrollar estrategias para los servicios o bienes que producen ${ }^{11}$, sin la Ética como pilar fundamental en la formación del informador, sea periodista o sea documentalista es imposible partir de una buena enseñanza de la comunicación. Considero que debe ser incluida como disciplina importante en el aprendizaje de la profesión. Sin la Ética no existirán principios informativos aprendidos, reflexionados, argumentados y posteriormente aplicados a la información. Pero con ella el resultado del trabajo será limpio, honesto y verídico, en definitiva objetivo y producirá un mensaje con esas cualidades y germinará un documento real, fiel a la noticia y al acontecimiento.

La evolución de las Tecnologías de la Información y la Comunicación (TIC), Internet y la digitalización de la información han facilitado el acceso a la información y su extensión pero también ha ocasionado otros problemas de vital trascendencia que dificultan la objetividad. Los principales problemas éticos aparecidos debido al propio desarrollo y utilización de las TIC y especialmente de Internet y la World Wide Web, están referidos entre otras cuestiones a la privacidad, el control y vigilancia en el lugar de trabajo, los derechos de propiedad intelectual, la seguridad informática, el acceso y poder a los sistemas informáticos, la globalización y la responsabilidad moral y profesional ${ }^{2}$ Es indispensable conocer para poder actuar bien. Si no tenemos conocimiento de los hechos el comportamiento malo ronda nuestra conducta, si por el contrario estamos bien documentados y conocemos la mayoría de los hechos contrastándolos con las fuentes, será más fácil que el producto informativo sea bueno y fidedigno.

${ }^{11}$ Rojas Mesa, Y., Cabrales Hernández, G., Gregorio Chaviano, O., Santos Jiménez, M. y Molina Gómez, A.: La ética: un nuevo reto para el profesional de la información del siglo XXI. ACIMED (ISSN 1024-9435) V.12n.2- Ciudad de La Habana, mar-abr 2004

www.absysnet.com.bibliotecasescolares

${ }^{12}$ González Guitián, M ${ }^{\mathrm{a}}$ V. y Martínez Ríos, M.A.: "El profesional de la Información y el comportamiento ético en el contexto actual, en Contribuciones a las Ciencias Sociales, noviembre 2009.

www.eumed.net/rev/cccss/06/ggmr.htm 


\section{CONCLUSIONES:}

- La Moral tiene una base social porque es un conjunto de normas establecidas ya en el seno de una sociedad, en cambio la Ética surge desde la interioridad de las personas, como resultado de su propia reflexión y de su propia elección.

- Sin la Ética no existirán principios informativos aprendidos, reflexionados, argumentados y posteriormente aplicados a la información. Pero con ella el resultado del trabajo será limpio, honesto y verídico, en definitiva objetivo y producirá un mensaje con esas cualidades y germinará un documento real, fiel a la noticia y al acontecimiento.

- Si el usuario dicta que es relevante para él y que demanda al informador, el profesional ha de tener claro sus valores morales y tratar éticamente la información y el documento que ofrece, si por el contrario se deja influenciar por las circunstancias exógenas al hecho en sí, estará decorando la realidad a su gusto y medida.

- Con la explosión de las nuevas tecnologías, la barrera que distingue lo correcto de lo incorrecto se ha difuminado.

- Si no tenemos conocimiento de los hechos el comportamiento malo ronda nuestra conducta, si por el contrario estamos bien documentados y conocemos la mayoría de los hechos contrastándolos con las fuentes, será más fácil que el producto informativo sea bueno y fidedigno.

- El trabajo del documentalista de información ha de plasmar el mundo tal como es sin aditivos para que pase a la historia como un mensaje informativo de lo que realmente ha pasado, lo que está aconteciendo delante de nuestros ojos y oídos y que en poco tiempo si no se capta se convierte en olvido, sin aditivos ni colorantes sin malear sin imprimirle el sello personal, tal y como ocurre, tal y como fue, es y será.

- El profesional de la información ha de pensar detenidamente antes de informar y emitir sus contenidos, ya que de sus actuaciones dependerán muchos comportamientos. En definitiva, ha de realizar el esfuerzo de cumplir con su ética.

\section{REFERENCIAS BIBLIOGRÁFICAS}

CUENCA MOLINA, Ángel: ÉTICA DE LA COMUNICACIÓN. Anales de Documentación, $\mathrm{n}^{\circ}$ 2, 1999, pp. 16-17 
FROEHLICH, THOMAS J.: Ética e información, artículo EL PROFESIONAL DE LA INFORMACIÓN; 1995

www.elprofesionaldelainformación.com/contenidos/1995/septiembre/tica_e_inf GARCÍA GUTIÉRREZ, A.: "Notas sobre procesos reflexivos y funciones en los nuevos especialistas de información: aproximación a los perfiles formativo e investigador". ÁMBITOS No 3-4, $2^{\circ}$ semestre 1999-1º semestre 2000 (pp. 3341)

GONZÁLEZ GUITIÁN, Ma V. Y MARTÍNEZ RÍOS, M.A.: "El profesional de la Información y el comportamiento ético en el contexto actual, en Contribuciones a las Ciencias Sociales, noviembre 2009

www.eumed.net/rev/cccss/06/ggmr.htm

Idcupn.files.wordpress.com/.../definición-de-ética

MUÑOZ MOLINA, A.: Memoria fotográfica; artículo periódico EL PAÍS; 5 abril 2008

RODRÍGUEZ SÁNCHEZ, MESA FLEITAS, E. y ÁLVAREZ SOLÓRZANO: La ética del profesional de la información ante la nueva sociedad del conocimiento. ACIMED 2006, 14(1)

http://bvs.sld.cu/revistas/aci/vol14_1_06/aci12106.htm

ROJAS MESA, CABRALES HERTÁNAEZ, G., GREGORIO CHAVIANO, O., SANTOS JIMÉNEZ, M. y MOLINA GÓMEZ, A.: La ética: un nuevo reto para el profesional de la información del siglo XXI. ACIMED (ISSN 1024-9435) v.12n.2- Ciudad de La Habana, mar-abr. 2004

Servimedia, Estudio de Comunicación y colaboración de FAPE: "La ética en la empresa periodística y su profesionales" (Estudio conjunto, julio de 2012; 25 aniversario cursos de verano Universidad Complutense, San Lorenzo del Escorial)

Special Libraries Association: ABELS, E., JONES, R., LATHAM, J. MAGNONI, D. GARD MARSHALL, J., traducido al español por Lau, J.: Competencias para profesionales de la información del siglo XXI, junio 2003

http://www.sld.cu/galerias/pdf/sitios/bmn/competencias_profesionales_trabajadore s_informacion_sla.pdf 